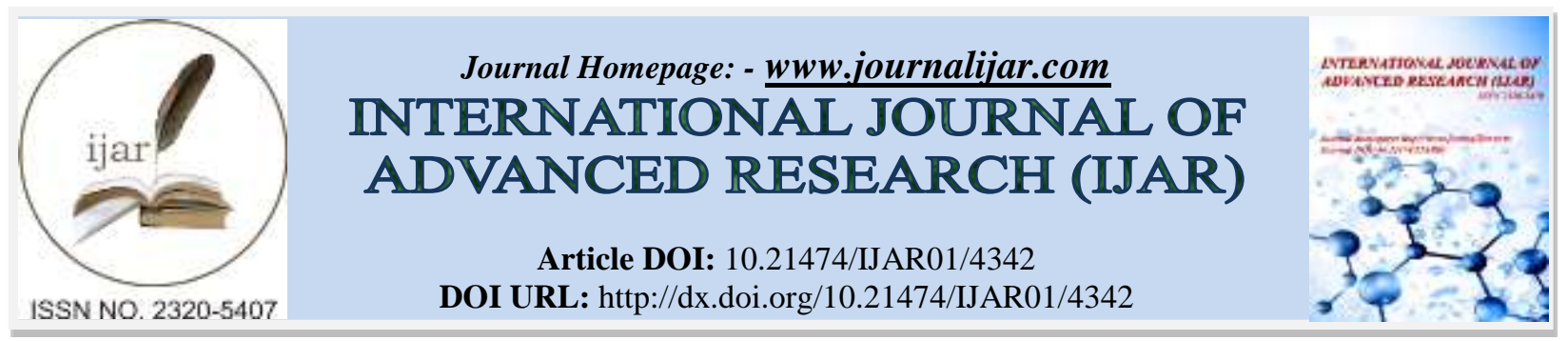

RESEARCH ARTICLE

\title{
A STUDY OF MENTAL TOUGHNESS IN TALENTED KABADDI PLAYERS.
}

\author{
Shantanu Sana ${ }^{1}$ and Dr. Yuwraj Shrivastava ${ }^{2}$. \\ 1. M.Phil. Student, Dr. C.V. Raman University, Kota Bilaspur C.G. \\ 2. Assistant Professor, Department of Physical Education, Dr. C.V. Raman University, Kota Bilaspur C.G.
}

\section{Manuscript Info}

Manuscript History

Received: 16 March 2017

Final Accepted: 18 April 2017

Published: May 2017

\section{Abstract}

The aim of the present study is to comparatively assess mental toughness in talented male kabaddi players. 50 national/international level male kabaddi players (Ave. age 26.22 yrs.) was selected and termed as talented male kabaddi players. To fulfil the objectives of the present study another set of 50 district level male kabaddi players (Ave. age 21.98 yrs) was also selected. The age range of the selected subjects was between 18-28 years. The sample was collected through convenience sampling method. Mental Toughness Questionnaire prepared by Tiwari (2007) was used to assess mental toughness of selected male kabaddi players. Results indicate that national/international male kabaddi players showed more magnitude of mental toughness as compared to district level male kabaddi players at .05 level of statistical significance. It was concluded that that apart from other factors superior mental toughness too is important to excel in sports such as kabaddi.

Copy Right, IJAR, 2016,. All rights reserved.

\section{Introduction:-}

Undoubtedly India reigns supreme in kabaddi. Since its introduction in Asian games and start of kabaddi world cup, India was almost unbeatable. They are the world cup champions in both men and women category. But things are changing rapidly as is evident from the fact the India lost a league game and the match with Iran was a close one. Hence the gap between India and other countries is fast becoming narrow. It may be argued that Indian kabaddi players are leagues ahead as far as skill is concerned but it is necessary to evaluate the psychological potentiality of kabaddi players. The psychological assessment in the form of mental toughness may be used in this connection. To keep ahead in every aspect of performance in Kabaddi, psychological data is also useful. In recent times mental toughness has emerged as major psychological variable for consistent performance. Researchers like Crust (2008), Jones et al. (2007) have reported confidence, self belief and ability to accept challenges as important psychological variables of mental toughness paradigm. Clough et al. (2002) reported that people who are mentally tough have a high sense of self-belief and an unshakable faith that they control their own destiny; these individuals can remain relatively unaffected by competition and adversity.

It is also noticeable that mental toughness has been studied extensively by researchers such as Golby \& Sheard, (2004), Kuan and Roy (2007), Rathore, Singh and Dubey (2009), Dubey and Singh (2014) but no study yet has been conducted with kabaddi as central theme. In view of this, the researcher decided to compare mental toughness between national/international and district level male kabaddi players. 


\section{Hypothesis:-}

It was hypothesized that national / international male Kabaddi players will show more magnitude of mental toughness as compared to district level male kabaddi players.

\section{Methodology:-}

The following methodological steps were taken in order to conduct the present study.

\section{Sample:-}

50 national/international level male kabaddi players (Ave. age 26.22 yrs.) was selected and termed as talented male kabaddi players. To fulfil the objectives of the present study another set of 50 district level male kabaddi players (Ave. age 21.98 yrs) was also selected. The age range of the selected subjects was between 18-28 years. The sample was collected through convenience sampling method.

\section{Tools:-}

\section{Mental Toughness Questionnaire:-}

To assess mental toughness of selected male kabaddi players, Mental Toughness Questionnaire prepared by Tiwari (2007) was used. It consists of 48 items which measures overall mental toughness and sub variables i.e. self confidence, motivation, attention control, goal setting, visual and imagery control and attitude control. The minimum score of 48 and maximum score of 240 can be obtained in this questionnaire. Higher the score, better the mental toughness is the direction of the study. This test is highly reliable and valid.

\section{Procedure:-}

After selection of sample and fulfilling ethical considerations mental toughness questionnaire was administered to each subject.

After this, the scoring was completed according to the scoring system prescribed by the author of the scale. Then the data was tabulated according to their groups. Independent sample ' $t$ ' test was used to compare mental toughness between two study groups. The results shown in table 1

\section{Result and Discussion:-}

Table 4:- Comparison of Mental Toughness between National/International and District Level Male Kabaddi Players

\begin{tabular}{|l|l|l|l|l|l|l|}
\hline \multirow{3}{*}{ Groups } & \multicolumn{2}{|l|}{$\begin{array}{l}\text { National/International Level } \\
\text { Male Kabaddi Players (N=50) }\end{array}$} & $\begin{array}{l}\text { District Level Male } \\
\text { Kabaddi Players (N=50) }\end{array}$ & $\begin{array}{l}\text { Mean } \\
\text {.Diff }\end{array}$ & ' $\mathrm{t}^{\circ}$ \\
\cline { 2 - 5 } & Mean & .S.D & Mean & .S.D & & \\
\hline $\begin{array}{l}\text { Mental } \\
\text { Toughness }\end{array}$ & 200.60 & 24.90 & 185.36 & 37.93 & 15.24 & $\begin{array}{l}2.37 \\
(\mathrm{p}<.05)\end{array}$ \\
\hline
\end{tabular}

at .01 level Significant $* *$

Perusal of statistical entries reported in table 1 reveal significant difference in mental toughness of national/international and district level male kabaddi players. Calculated $t=2.37$ depicted in table 4 indicate that national/international male kabaddi players have more magnitude of mental toughness $(\mathrm{M}=200.60)$ as compared to district level male kabaddi players $(\mathrm{M}=185.36)$ at .05 level of statistical significance.

\section{Conclusion:-}

Results shown in table 1 is an indicator of fact that national/international level male kabaddi players are mentally more tough as compared to district level male kabaddi players at acceptable level of statistical significance. Since mental toughness encompasses wide range of psychological variables such as self confidence, visual and imagery control, coping skills, competitiveness etc. hence there is no surprises in results. Results obtained by Golby \& Sheared (2004), Kuan and Roy (2007), Sheard (2009) also reiterates the fact the mental toughness is the key to performance in kabaddi. 


\section{References:-}

1. Clough, P., Earle, K. and Sewell, D. (2002). Mental toughness: the concept and its measurement. In I. Cockerill (Ed.), Solutions in sport psychology, (pp. 32-43). London: Thomson.

2. Crust, L. (2008). A review and conceptual re-examination of mental toughness: Implications for future researchers. Personality and Individual Differences, 45, 576-583.

3. Crust, L. and Azadi, K. (2010). Mental toughness. European Journal of Sport Science, 10, 43-51.

4. Dubey, S. and Singh, M.K. (2014). Comparative study of mental toughness between sub-junior national male and female baseball players. Golden Research Thoughts, Vol. 4, Issue 4, 1-3.

5. Golby, S. (2004). Mental toughness and hardiness at different levels of rugby league. Journal of Personality and individual differences. 37: 933-944.

6. Jones, G., Hanton, S. and Connaughton, D. (2007). A framework of mental toughness in the world's best performers. The Sport Psychologist, 21, 243-264.

7. Jones, G.; Hanton, S.; Connaughton, D. (2002). "What Is This Thing Called Mental Toughness? An Investigation of Elite Sport Performers". Journal of Applied Sport Psychology 14 (3): 205-218.

8. Kuan, G. and Roy, J. (2007). Goal Profiles, Mental Toughness and its Influence on Performance Outcomes among Wushu Athletes. Journal of Sports Science and Medicine, 6(2), 28-33.

9. Rathore, M. S., Singh, Y. P., \& Dubey, A. (2009). A Comparative Study of Mental Toughness of the Team and Individual Players of Different C.B.S.E. Schools of Rajasthan. Proceedings of India International Congress in Sport Psychology (Excellence in Sport and Life). Tapp, J. (1991). Mental Toughness. Referee, 16, 44-48.

10. Sheard, M. (2009). A cross-national analysis of mental toughness and hardiness in elite university rugby league teams. .223-ills: Volume 109, Issue 1, pp. 213Perceptual and Motor Sk 